\title{
The Presence and Characterization of a virF Gene on Agrobacterium vitis Ti Plasmids
}

\author{
B. Schrammeijer, J. Hemelaar, and P. J. J. Hooykaas \\ Institute of Molecular Plant Sciences, Clusius Laboratory, Leiden University, Wassenaarseweg 64, $2333 \mathrm{AL}$ \\ Leiden, The Netherlands \\ Accepted 28 January 1998
}

\begin{abstract}
Octopine and nopaline strains of Agrobacterium tumefaciens differ in their ability to induce tumors on Nicotiana glauca. The presence of a virF locus on the octopine $\mathrm{Ti}$ plasmid makes $N$. glauca a host plant for these strains, indicating that the VirF protein is a host-range determinant. Here we show the presence of a virF locus not only on the Agrobacterium vitis octopine/cucumopine plasmids pTiAg57 and pTiTm4, but also on the nopaline Ti plasmids pTiAT1, pTiAT66 ${ }^{\mathrm{a}}$, and pTiAT66 ${ }^{\mathrm{b}}$. On the octopine Ti plasmids from $A$. tumefaciens the virF gene is located between the virE locus and the left border of the T-region. In contrast, the virF gene on Ti plasmids of $A$. vitis is located at the very left end of the vir-region near the virA locus. The virF gene of pTiAg57 has been sequenced and codes for a protein of $\mathbf{2 0 2}$ amino acids with a molecular mass of 22,280 Da. Comparison showed that the virF gene from $A$. vitis strain Ag57 is almost identical to that from $A$. tumefaciens octopine strains. The transcription of the pTiAg57 virF is inducible by the plant phenolic compound acetosyringone through the presence of a vir-box consensus sequence in its promoter region. The VirF protein from pTiAg57 can complement octopine A. tumefaciens strains deleted for virF as shown by tumor formation on N. glauca.
\end{abstract}

The gram-negative soil bacterium Agrobacterium tumefaciens induces the plant tumor crown gall in dicotyledonous plants (for a review, see Hooykaas and Beijersbergen 1994). A. tumefaciens contains a tumor-inducing (Ti) plasmid, part of which, the transferred (T)-region, is introduced into plant cells during tumorigenesis. On this T-region oncogenes are present that are responsible for the tumorous phenotype of the transformed plant cells. Furthermore, there are genes located on the T-region coding for enzymes that mediate the formation of certain tumor-specific metabolites called opines. Based on the specific opine(s) produced in the tumors, strains can be classified as, e.g., octopine, nopaline, leucinopine, vitopine types. The vir-region, which is also located on the Ti-plasmid, de-

Corresponding author: P. J. J. Hooykaas; Telephone: (31) 71527 4933; Fax: (31) 71527 4999; E-mail: hooykaas@ rulbim.leidenuniv.nl

Nucleotide and amino acid sequence data are to be found at GenBank as accesssion number AT044200. termines the transfer system. Three biotypes, I, II, and III, can be distinguished in Agrobacterium based on chromosomal characteristics (Kerr and Panagopoulos 1977). A. tumefaciens biotype III was given the new species name $A$. vitis because of its specific association with Vitis vinifera (grapevine) plants (Ophel and Kerr 1990). Both octopine and nopaline strains of A. tumefaciens have a wide host range for tumor induction, but show a difference in virulence toward Nicotiana glauca. This is due to the absence of the virF locus from the nopaline Ti plasmid (Otten et al. 1985; Melchers et al. 1990). The octopine virF locus codes for one protein that has an unknown function in the transformed plant cells (Regensburg-Tuïnk and Hooykaas 1993). Because of these interesting properties of virF we have studied the gene in more detail. Here we report the presence of virF in A. vitis, as well as the characteristics of an $A$. vitis virF gene.

To analyze for the presence of a virF gene on the Ti plasmids of different $A$. vitis strains, Ti plasmid preparations were obtained as described by Den Dulk-Ras and Hooykaas (1995) from strains containing the octopine/cucumopine pTiAg57 and pTiTm4, the nopaline pTiAT1, pTiAT66 ${ }^{\mathrm{a}}$, and pTiAT66 ${ }^{\mathrm{b}}$, and the vitopine pTiS4 and pTiSz1 plasmids (Szegedi et al. 1988). The A. tumefaciens octopine pTiB6, which is almost identical to pTi15955, and the nopaline pTiC58 plasmids were isolated as controls. Southern blot analysis with virF from pTi15955 as a probe showed no hybridization for the nopaline pTiC58 plasmid (negative control) or for the vitopine Ti plasmids under the conditions used ( $\geq 68 \%$ homology) (Fig. 1). The positive control pTiB6 gave a hybridizing signal as expected. In addition, a signal, although less strong, was observed not only for the octopine/cucumopine but also for the nopaline $\mathrm{Ti}$ plasmids of A. vitis (Fig. 1). The virF gene is present on a 4.5$\mathrm{kb}$ HindIII and a 3.3-kb PstI fragment in all these plasmids and on 5.6-kb and 9.4-kb EcoRI fragments for, respectively, the octopine/cucumopine and nopaline plasmids. Gérard and co-workers (1992) have shown that the restriction maps of the octopine/cucumopine and nopaline Ti plasmids of $A$. vitis are similar in the virulence region, but different from that of the vitopine plasmid pTiS4. Therefore, virF is apparently present in this region, which is conserved between $A$. vitis octopine/ cucumopine and nopaline Ti plasmids. The difference in the map of the vitopine Ti plasmid could also be an indication for the absence of virF. However, the presence of a more heterologous virF gene on these vitopine-type Ti plasmids cannot 
be excluded. The virF gene located on pTiAg57 was subcloned from pAH11 (Van Nuenen et al. 1993) as a 2.3-kb HindIII/PstI fragment in pBluescriptII SK $\mathrm{SK}^{-}$(pRAL7089) for sequence analysis (Table 1). Cloning was confirmed by Southern blot analysis with the pTi15955 virF gene as a probe (data not shown). A series of $5^{\prime}$ deletions for both the upper and lower strands of the 2.3-kb insert in pRAL7089 was made with the Erase-a-Base procedure (Promega, Madison, WI). Polymerase chain reaction analysis with the virF-specific primers was done to locate the virF homologue within both series of deletions. The nucleotide sequence of $922 \mathrm{bp}$ of the 2.3-kb HindIII/PstI insert of pRAL7089 is shown in Figure 2. The DNA and protein sequences were analyzed with the GAP, MAP, PEPTIDESORT, and TRANSLATE programs of the University of Wisconsin-Madison Genetics Computing
Group. The VirF proteins from pTiAg57 and pTi15955 both consist of 202 amino acids and have similar molecular masses of 22,280 and 22,437 Da, respectively. The proteins differ in net charge: minus five for pTiAg57 VirF and zero for pTi15955 VirF. The virF gene on pTiAg57 is preceded by a vir-box at position -67 to -80 that is $100 \%$ identical to the virbox of the virF gene from pTi15955 (data not shown). Comparison of the virF gene from pTiAg57 and pTi15955 at DNA and protein levels showed remarkably high percentage identities of 86 and $84 \%$, respectively. Differences caused by base pair substitution(s) are randomly distributed throughout the open reading frame (data not shown). Comparison of the $5^{\prime}$ noncoding region of both virF genes showed a high identity of $82 \%$, whereas the $3^{\prime}$ noncoding region is more diverged (only $44 \%$ identical). Using the restriction map of the pTiAg57

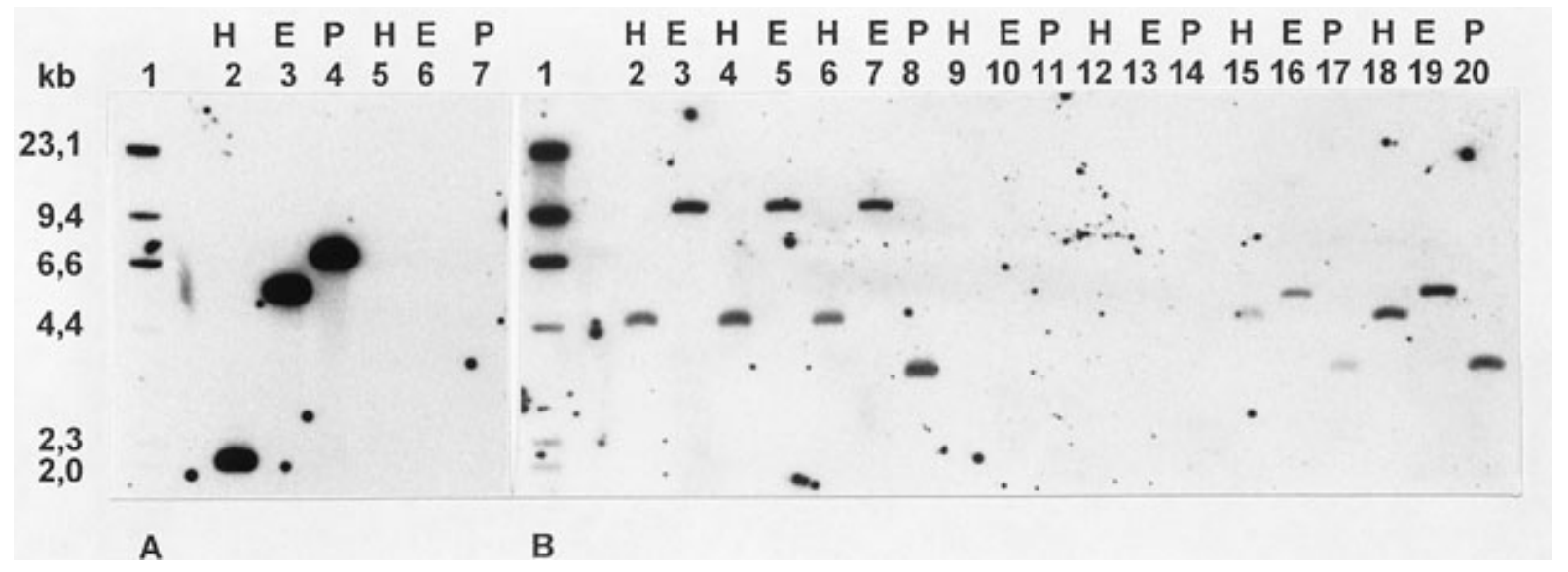

Fig. 1. Southern blot analysis of Ti plasmids from Agrobacterium tumefaciens and A. vitis. A, Lane1: digoxigenin (DIG) DNA marker; lanes 2, 3, 4: pTiB6; lanes 5, 6, 7: pTiC58. B, Lane 1: DIG DNA marker; lanes 2, 3: pTiAT1; lanes 4, 5: pTiAT66a ; lanes 6, 7, 8: pTiAT66 ${ }^{\text {; }}$ lanes 9, 10, 11: pTiS4; lanes 12, 13, 14: pTiSz1; lanes 15, 16, 17: pTiTm4; lanes 18, 19, 20: pTiAg57. Restriction enzyme-digested Ti plasmids were separated on a 0.8\% TAE (40 mM Tris-acetate $\mathrm{pH} 7.6$, and $7 \mathrm{mM}$ EDTA) agarose gel and transferred to a positively charged membrane (Boehringer Mannheim, Almere, The Netherlands). For non-radioactive analysis, the DIG protocol (Boehringer Mannheim) was used with the DIG-11-dUTP randomly labeled 500-bp EcoRI/XhoI virF fragment from pRAL7088 as probe. In lanes 15, 16, and 17 a smaller amount of DNA was loaded. The blot in B was exposed longer than the blot in A (as seen in the DIG DNA marker lanes). Restriction enzymes (Pharmacia Biotech, Roosendaal, The Netherlands): H: HindIII; E: EcoRI; and P: PstI.

Table 1. Bacterial strains and plasmids

\begin{tabular}{|c|c|c|}
\hline Plasmid/strain & Characteristics & References \\
\hline $\begin{array}{c}\text { Escherichia coli }^{\mathrm{a}} \\
\text { DH5 } \alpha(\mathrm{K} 12)\end{array}$ & & Gibco BRL, Breda, The Netherlands \\
\hline $\begin{array}{l}\text { Agrobacterium tumef } \\
\text { LBA288 } \\
\text { LBA1010 } \\
\text { LBA1100 } \\
\text { LBA2560 } \\
\text { LBA2561 } \\
\text { LBA2562 } \\
\text { LBA2563 }\end{array}$ &  & $\begin{array}{l}\text { Hooykaas et al. } 1979 \\
\text { Koekman et al. } 1982 \\
\text { Beijersbergen et al. } 1992 \\
\text { B. Schrammeijer, unpublished } \\
\text { B. Schrammeijer, unpublished } \\
\text { This study } \\
\text { This study }\end{array}$ \\
\hline $\begin{array}{l}\text { Plasmid } \\
\text { pBluescriptII SK- } \\
\text { pIC19R } \\
\text { pUC18 } \\
\text { pUC19 } \\
\text { pAH11 } \\
\text { pRAL7007 } \\
\text { pRAL7088 } \\
\text { pRAL7089 }\end{array}$ & $\begin{array}{l}\mathrm{Cb}^{\mathrm{r}} \\
\mathrm{Cb}^{\mathrm{r}} \\
\mathrm{Cb}^{\mathrm{r}} \\
\mathrm{Cb}^{\mathrm{r}} \\
\text { pUC18, 31.1-kb HindIII fragment from pTiAg57 } \\
\text { pIC19R, 2.0-kb SacI fragment from EcoRI-11 of plasmid pTi15955 } \\
\text { pUC19, 2.0-kb SacI fragment from pRAL7007 } \\
\text { pBluescriptII SK }, 2.3-\mathrm{kb} \text { HindIII/PstI fragment from pAH11 }\end{array}$ & $\begin{array}{l}\text { Alting-Mees and Short } 1989 \\
\text { Marsh et al. } 1984 \\
\text { Yanisch-Perron et al. } 1985 \\
\text { Yanisch-Perron et al. } 1985 \\
\text { Van Nuenen et al. } 1993 \\
\text { Melchers et al. } 1990 \\
\text { B. Schrammeijer, unpublished } \\
\text { This study }\end{array}$ \\
\hline
\end{tabular}

${ }^{\mathrm{a}} \mathrm{Cb}$ : carbenicillin $(100 \mu \mathrm{g} / \mathrm{ml})$.

${ }^{\text {b }}$ Cb: carbenicillin $(75 \mu \mathrm{g} / \mathrm{ml})$; Rif: rifampicin $(20 \mu \mathrm{g} / \mathrm{ml})$; and Sp: spectinomycin $(250 \mu \mathrm{g} / \mathrm{ml})$. 
plasmid (Van Nuenen et al. 1993; Otten and De Ruffray 1994), we have found that the virF gene is located at the very left end of the vir-region near the virA locus and reads from left to right toward the $\mathrm{T}_{\mathrm{A}}$-region. In contrast, the virF on pTi15955 is located between the virE locus and the left border of the T-region. One explanation for the difference in location of virF could be transposition or recombination of the gene itself, although no indications were obtained for this by ana-

1 ttttcttagctgcgtcggaagatggccagaccaac

37 gctttgatgatgccgaagctgatcaattgtgccgta

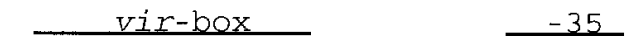

73 aaactacaatgaadagaaaattcttaatcgtct

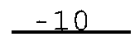

109 ccacccgagtagcatattatccttgatgaacaaag RBS VirF

143 gagcgatatcATGAGAAATTCGAGTTTGCATGATGC

181 ATCTGGGAACGACGATGCACAGGTACCCCACAAAAC

217 AGAATTGCTTGATCTGCCAGACCTTGTGCTGACGGA

253 AGTTGCCAAACGTCTAGCGACTGACAATCCAGTTGA

289 GTCCGCGGAGAATATAGCTAATTTTAGCAAATCCCA

325 TCGCTCGACAAGGGACGTGGTTCGAACGGAACCTTT

361 AGAAAAATTCTCGTCACGCCTTAAGATCCTGGCGCC

397 ACAGGCGAAACTGTTGTGTCATGCCGTGCGGCAGGC

433 AGCAACACTGCCGGATGGAGAACAACTAAGTGAAGC

469 GCAACTATTGCAAATGCAAAATGAAGTCGCAATTCG

505 CCCAGTCTTAGGCGTAGCGTATACCCATCACGACGG

541 CCAACCAGGAGAGAGTTTGTCAGGGAACGACCTGAA

577 CCGTAAAATTGAGAATATTCCTGATTTGGTCTTCAA

613 TGTTGCGGAACCCATTATGTTTAATGAGATCTCCGC

649 TACCGAGGTGATGGCAAAAGTTCGGCCTATCGCCAG

685 ATCGATCAAAGAGGCCCACGACAATGCGCGAGCGGA

721 ATTGATGTCGGTGGAAAGGCCTCGAGGAACGCGCGG

757 TCTATGActatatgcgctcttcgacgcgcgcctaga

793 aggacctgctcgcactctcttaagactggcgggtt

829 gggtacacgcggcctgatctgatgggggccaggttt

865 gcgacttggtgctcgcgaccttcgtgcgtctgagt

902 aatcacggggagatggagcca 922

Fig. 2. Nucleotide wsequence of a 922-bp fragment from pTiAg57 containing the $\operatorname{vir} F$ gene. Open reading frame of virF is presented in bold and uppercase letters. Positions of the vir-box, the -10 and -35 promoter sequences, and the putative ribosome binding site (RBS) are indicated with a black bar. Sequence analysis was performed as described by Sanger et al. (1977) with the T7 polymerase DNA and deazaDNA sequencing kit (Pharmacia Biotech, Roosendaal, The Netherlands). Nucleotide and/or amino acid sequence data are to be found at GenBank as accesssion number AT044200. lyzing the virF flanking sequences on pTiAg57 and pTi15955 for such events. Another explanation might be movement of the vir-region as a whole from one replicon to another by circularization on the ends and integration and linearization with slightly different ends. As a result, the order of the vir-loci can permutate depending on the break points within the vir-region.

To determine whether the expression of virF from pTiAg57 could be induced by acetosyringone (AS) the $v i r F$ gene behind its own promoter, including the vir-box, was introduced in the A. tumefaciens virF deletion mutant LBA2560 as well as the virF deletion helper strain LBA2561, resulting in strains LBA2562 and LBA2563, respectively. Western blot (immunoblot) analysis (Fig. 3) showed for the control oncogenic octopine strain LBA1010 (C58 cured with pTiB6) and helper strain LBA1100 after induction with AS (Turk et al. 1993) expression of the VirF protein, whereas no VirF was produced in the AS-induced virF deletion mutants LBA2560 and LBA2561. The pTiAg57 VirF could be detected in the
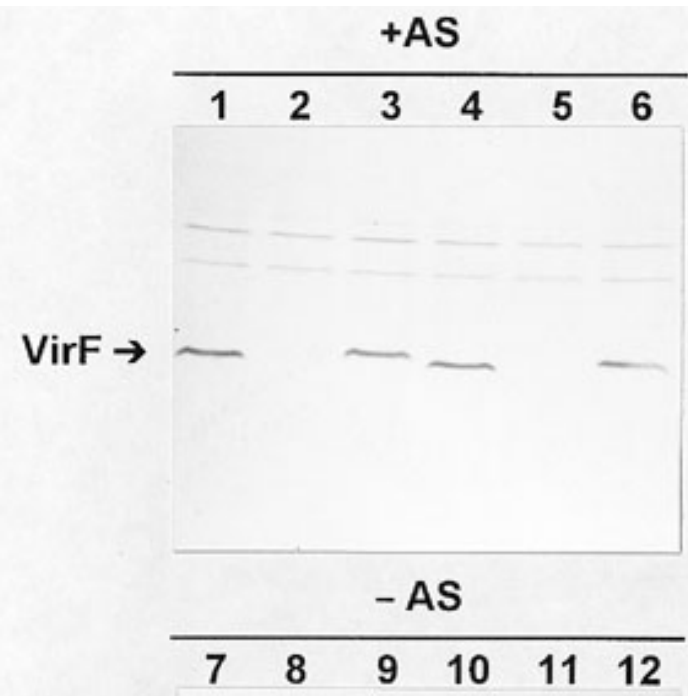

Fig. 3. Detection of the VirF protein in different Agrobacterium tumefaciens strains by Western blot (immunoblot) analysis. Lanes 1, 7: LBA1010 (C58 cured, pTiB6); lanes 2, 8: LBA2560 (LBA1010 AvirF); lanes 3, 9: LBA2562 (LBA2560::pTiAg57virF); lanes 4, 10: LBA1100 (helper); lanes 5, 11: LBA2561 (LBA1100 $v$ virF); and lanes 6, 12: LBA2563 (LBA2561::pTiAg57virF). Total protein extracts were loaded on a $12.5 \%$ sodium dodecyl sulfate-polyacrylamide gel electrophoresis gel; after electrophoresis, proteins were transferred to an Immobilon-P membrane (Millipore, Bedford, MA). Position of the VirF protein is indicated with an arrow. +AS: cells grown in the presence of $200 \mu \mathrm{M}$ acetosyringone; -AS: cells grown in the absence of acetosyringone. Polyclonal antibodies were used that had been raised against the VirF protein from pTi15955. 
strains LBA2562 and LBA2563, but only after induction by $\mathrm{AS}$, indicating the presence of a functional vir-promoter. Based on these results, we can predict that the expression of the virF gene from pTiAg57 in A. vitis is also under the con- trol of a VirA/VirG two-component regulatory system that uses a vir-box identical to those of the vir genes in A. tumefaciens to modulate expression. In fact this is the first vir-box identified in a vir promoter located on an A. vitis octopine/

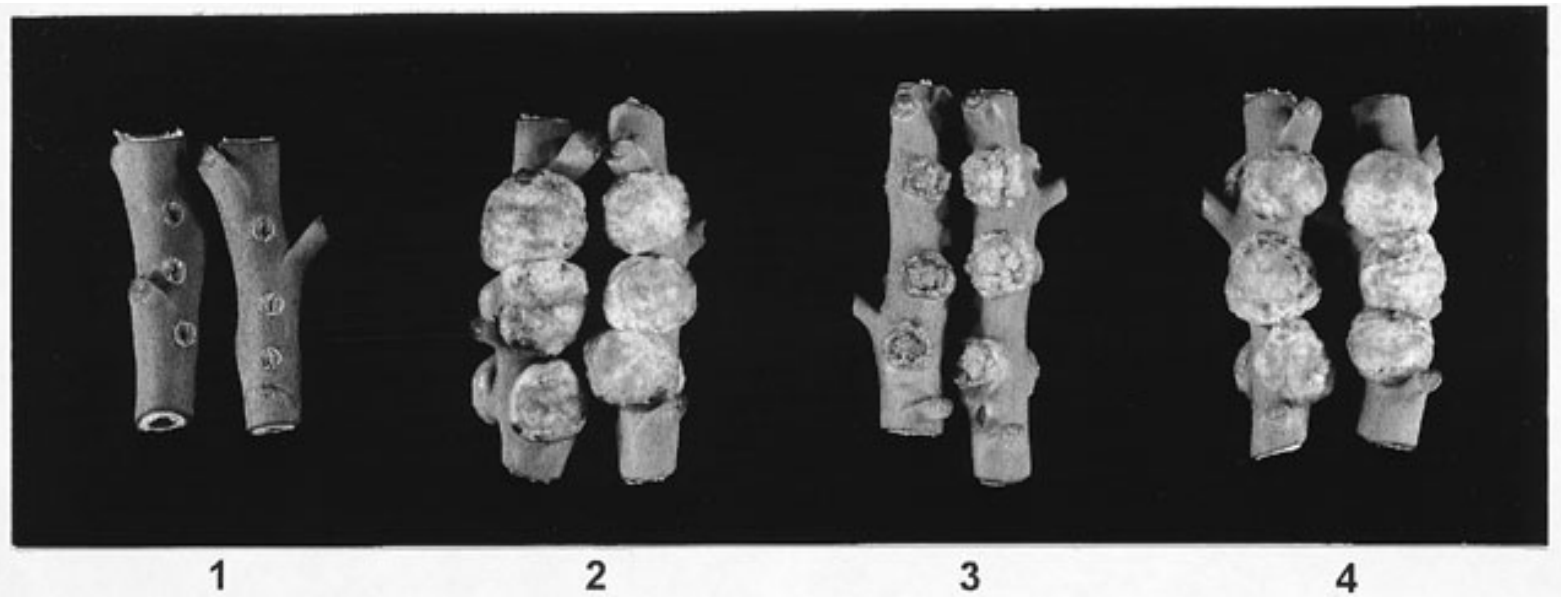

Fig. 4. Tumor formation on 2-month-old Nicotiana glauca stems by different Agrobacterium tumefaciens strains. 1: LBA288 (C58, pTi cured); 2: LBA1010 (LBA288+pTiB6); 3: LBA2560 (LBA1010 $\Delta v i r F)$; and 4: LBA2562 (LBA2560::pTiAg57virF). For inoculation, $20 \mu 1$ of bacteria culture $\left(\mathrm{OD}_{660}= \pm 1\right)$ was used per wound site. Tumor formation was scored 2 weeks post infection.

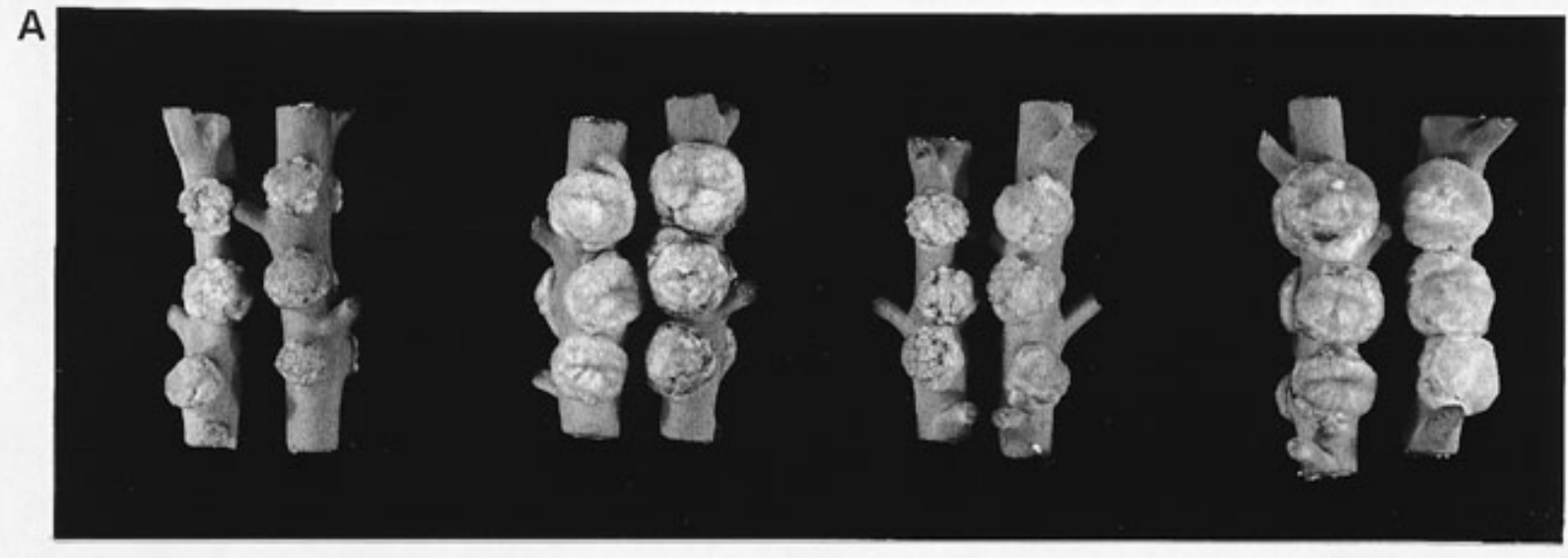

B

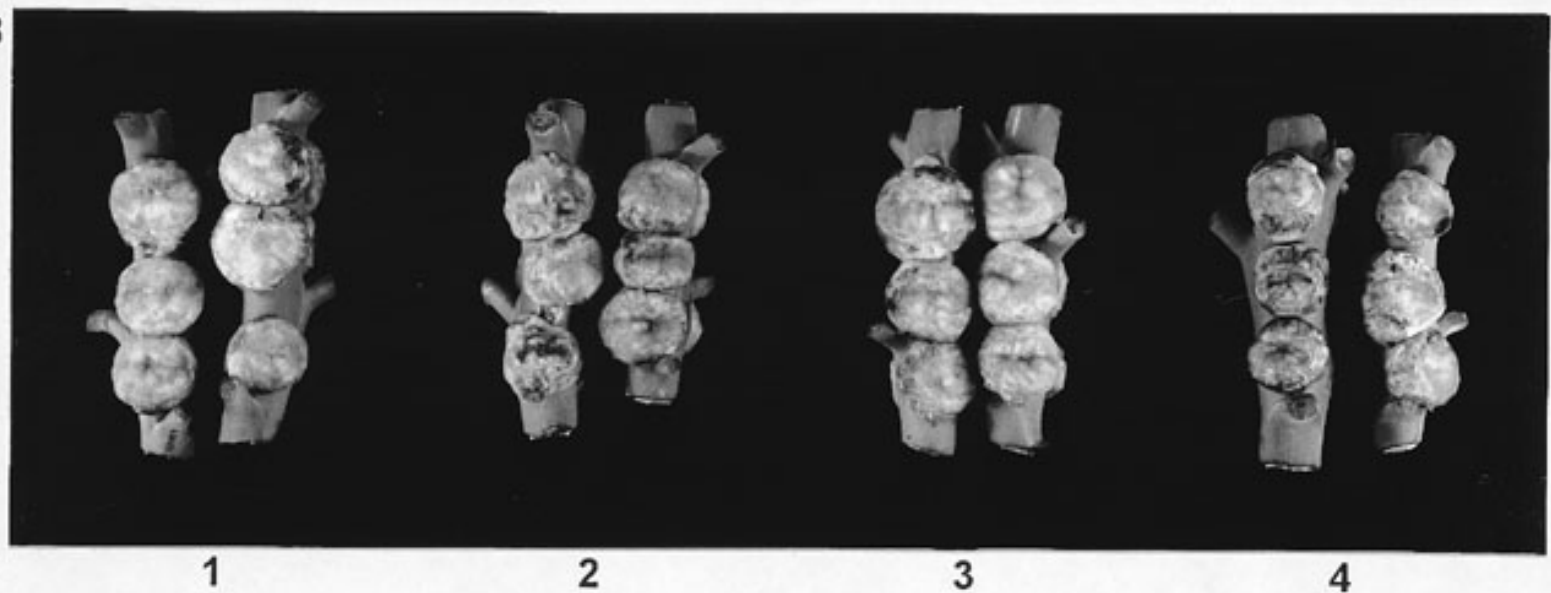

Fig. 5. "Extracellular" complementation for tumor formation on 2-month-old Nicotiana glauca stems. A, virF deletion mutant LBA2560 coinfected with

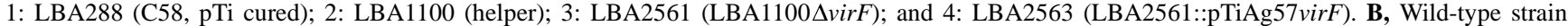
LBA1010 coinfected with 1: LBA288; 2: LBA1100; 3: LBA2561; and 4: LBA2563. For inoculation, the bacteria cultures $\left(\mathrm{OD}_{660}= \pm 1\right)$ were mixed in a 1:1 ratio, and $20 \mu \mathrm{l}$ of mixture was used per wound site. Tumor formation was scored 2 weeks post infection. 
cucumopine Ti plasmid that is induced by the plant phenolic compound AS.

A tumor assay on $N$. glauca was done to analyze VirF protein production and functioning in vivo. In agreement with previous results, infection of $N$. glauca with the virF deletion mutant LBA2560 resulted in a much smaller tumor compared with those provoked by the wild-type strain LBA1010 (Fig. 4). The integration of the pTiAg57 virF gene into LBA2560 (LBA2562), however, restored full tumorigenicity (Fig. 4). Coinfection of the virF deletion strain LBA2560 with helper strain LBA1100, containing the whole vir-region including virF but lacking the T-region, resulted in "extracellular" complementation for tumor formation on N. glauca (Fig. 5A). This is thought to be mediated by direct VirF protein transfer from bacteria to plant cells (Regensburg-Tuïnk and Hooykaas 1993). No "extracellular" complementation for tumor formation on $N$. glauca is achieved when LBA2560 is coinfected with the empty strain LBA288 or with the helper strain LBA2561, which is due to the absence of virF in these strains. However, the virF deletion strain LBA2560 can "extracellularly" be complemented by coinfection with the pTiAg57 virF containing helper strain LBA2563 (Fig. 5A), resulting in a similar tumor formation as when coinfected with helper strain LBA1100. Tumor formation by the wild-type strain LBA1010 was not influenced by the presence of any of these four helper strains (Fig. 5B). The above results indicate that expression of the virF gene from pTiAg57 results in a functional protein that can be transported to plant cells equally as well as the VirF protein from pTiB6.

Here we report the presence of a $\operatorname{virF}$ gene on two octopine/ cucumopine and three nopaline Ti plasmids of A. vitis. The virF gene on pTiAg57 is the second virulence gene located on an A. vitis octopine/cucumopine Ti plasmid, the DNA sequence of which has been determined. Earlier, Leroux and coworkers (1987) analyzed the DNA sequence of virA located on the A. vitis octopine/cucumopine Ti plasmid pTiAg162. This VirA protein turned out to share only $45 \%$ amino acid identity to the VirA protein of the octopine Ti plasmid pTiA6 of A. tumefaciens. The weak conservation in virA contrasts sharply with the strong conservation of virF. This strong conservation of VirF may suggest that the full-length protein is necessary for its function during tumorigenesis. The virF gene is present on the octopine pTi15955 but absent from the nopaline pTiC58 of A. tumefaciens. VirF is a host-range determinant that is necessary for full tumorigenicity on $N$. glauca (Melchers et al. 1990). The presence of virF on the octopine/ cucumopine and nopaline Ti plasmids of $A$. vitis may suggest that virF is also necessary for tumor formation on $V$. vinifera, although this has to be confirmed by further research.

\section{ACKNOWLEDGMENTS}

We thank L. Otten for providing the clone pAH11, E. Szegedi for donating the A. vitis strains, and Paul Bundock for critical reading of the manuscript. This work was supported by the Netherlands Foundation for Chemical Research (SON) with financial aid from the Netherlands Organization for Scientific Research (NWO).

\section{LITERATURE CITED}

Alting-Mees, M. A., and Short, J. M. 1989. pBluescript II: Gene mapping vectors. Nucleic Acids Res. 17:9494.

Beijersbergen, A., Den Dulk-Ras, A., Schilperoort, R. A., and Hooykaas, P. J. J. 1992. Conjugative transfer by the virulence system of Agrobacterium tumefaciens. Science 256:1324-1327.

Den Dulk-Ras, A., and Hooykaas, P. J. J. 1995. Electroporation of Agrobacterium tumefaciens. Pages 63-72 in: Methods in Molecular Biology 55: Plant Cell Electroporation and Electrofusion Protocols. J. A. Nickoloff, ed. Humana Press, Totowa, NJ.

Gérard, J-C, Canaday, J., Szegedi, E., De la Salle, H., and Otten, L. 1992. Physical map of the vitopine Ti plasmid pTiS4. Plasmid 28:146-156.

Hooykaas, P. J. J., and Beijersbergen, A. G. M. 1994. The virulence system of Agrobacterium tumefaciens. Annu. Rev. Phytopathol. 32: 157-179.

Hooykaas, P. J. J., Roobol, C., and Schilperoort, R. A. 1979. Regulation of the transfer of Ti plasmids of Agrobacterium tumefaciens. J. Gen. Microbiol. 110:99-109.

Kerr, A., and Panagopoulos, C. G. 1977. Biotypes of Agrobacterium radiobacter var. tumefaciens and their biological control. Phytopathol. Z. 90:172-179.

Koekman, B. P., Hooykaas, P. J. J., and Schilperoort, R. A. 1982. A functional map of the replicator region of the octopine Ti plasmid. Plasmid 7:119-132.

Leroux, B., Yanofsky, M. F., Winans, S. C., Ward, J. E., Ziegler, S. F., and Nester, E. W. 1987. Characterization of the virA locus of Agrobacterium tumefaciens: A transcriptional regulator and host range determinant. EMBO J. 6:849-856.

Marsh, J. L., Erfle, M., and Wykes, E. J. 1984. The pIC plasmid and phage vectors with versatile cloning sites for recombinant selection by insertional inactivation. Gene 32:481-485.

Melchers, L. S., Maroney, M. J., Den Dulk-Ras, A., Thompson, D. V., van Vuuren, H. A. J., Schilperoort, R. A., and Hooykaas, P. J. J. 1990. Octopine and nopaline strains of Agrobacterium tumefaciens differ in virulence; molecular characterization of the virF locus. Plant Mol. Biol. 14:249-259.

Ophel, K., and Kerr, A. 1990. Agrobacterium vitis sp. nov. strains of Agrobacterium biovar 3 from grapevines. Int. J. Syst. Bacteriol. 40: 236-241.

Otten, L., and De Ruffray, P. 1994. Agrobacterium vitis nopaline Ti plasmid pTiAB4: Relationship to other Ti plasmids and T-DNA structure. Mol. Gen. Genet. 245:493-505.

Otten, L., Piotrowiak, G., Hooykaas, P., Dubois, M., Szegedi, E., and Schell, J. 1985. Identification of an Agrobacterium tumefaciens pTiB6S3 vir region fragment that enhances the virulence of pTiC58. Mol. Gen. Genet. 199:189-193.

Regensburg-Tuïnk, A. J. G., and Hooykaas, P. J. J. 1993. Transgenic $N$. glauca plants expressing bacterial virulence gene virF are converted into hosts for nopaline strains of A. tumefaciens. Nature 363:69-70.

Sanger, F., Nicklen, S., and Coulson, A. R. 1977. DNA sequencing with chain-terminating inhibitors. Proc. Natl. Acad. Sci. USA 74:54635467.

Szegedi, E., Czakó, M., Otten, L., and Koncz, C. S. 1988. Opines in crown gall tumours induced by biotype 3 isolates of Agrobacterium tumefaciens. Physiol. Mol. Plant Pathol. 32:237-247.

Turk, S. C. H. J., Nester, E. W., and Hooykaas, P. J. J. 1993. The virA promoter is a host-range determinant in Agrobacterium tumefaciens. Mol. Microbiol. 7:719-724.

Van Nuenen, M., De Ruffray, P., and Otten, L. 1993. Rapid divergence of Agrobacterium vitis octopine-cucumopine Ti plasmids from a recent common ancestor. Mol. Gen. Genet. 240:49-57.

Yanisch-Perron, C., Vieira, J., and Messing, J. 1985. Improved M13 phage cloning vectors and host strains: Nucleotide sequences of the M13mp18 and pUC19 vectors. Gene 33:103-119. 